\title{
Royal Jelly Supplementation Improves Menopausal Symptoms Such as Backache, Low Back Pain, and Anxiety in Postmenopausal Japanese Women
}

\author{
Takashi Asama $\mathbb{D}^{1},{ }^{1}$ Hidenori Matsuzaki ${ }^{(D)},{ }^{1}$ Shinobu Fukushima ${ }^{(D)},{ }^{1}$ Tomoki Tatefuji ${ }^{1}{ }^{1}$ \\ Ken Hashimoto, ${ }^{1}$ and Takashi Takeda $\mathbb{D D}^{2}$ \\ ${ }^{1}$ Institute for Bee Products and Health Science, Yamada Bee Company, Inc., Okayama, Japan \\ ${ }^{2}$ Division of Women's Health, Research Institute of Traditional Asian Medicine, Kindai University, Osaka, Japan
}

Correspondence should be addressed to Takashi Asama; ta1022@yamada-bee.com

Received 24 January 2018; Accepted 27 March 2018; Published 29 April 2018

Academic Editor: Attila Hunyadi

Copyright (c) 2018 Takashi Asama et al. This is an open access article distributed under the Creative Commons Attribution License, which permits unrestricted use, distribution, and reproduction in any medium, provided the original work is properly cited.

Objectives. This study aimed to evaluate the effect of Royal Jelly (RJ) at a dose of $800 \mathrm{mg} /$ day on menopausal symptoms in healthy Japanese postmenopausal women with placebo-controlled design. Material and Methods. A total of 42 healthy Japanese postmenopausal women have been recruited for this study. The subjects were randomized to oral treatment with either $800 \mathrm{mg}$ of protease-digested lyophilized powder of RJ (enzyme-treated RJ) or placebo ( $800 \mathrm{mg}$ of dextrin) daily for 12 weeks. The level of menopausal symptoms has been evaluated every 4 weeks, using menopausal symptoms questionnaire of Japanese women. Independent $t$-test was used to evaluate statistical significance of the treatment effects between the two groups. Results and Conclusion. All of the 42 women have completed the trial. There were significant differences related to the anxiety score $(P=0.046)$ and backache and low back pain score $(P=0.040)$ between $800 \mathrm{mg} /$ day enzyme-treated RJ and placebo-treated groups after 12 weeks of administration, and no significant differences were found between the two groups in 4 weeks after intervention. No side effects were observed in either group. This study demonstrates that enzyme-treated RJ supplementation with doses of $800 \mathrm{mg} / \mathrm{day}$ is effective in relieving menopausal symptoms such as anxiety, backache, and low back pain in Japanese postmenopausal women.

\section{Introduction}

Menopause is a normal part of women's life, typically between ages 45 and 55 years, when the ovaries naturally stop producing eggs and their menstrual periods end. The decreased production of estrogen level affects autonomic nervous system, which can directly trigger menopause symptoms such as hot flashes, insomnia, mood changes, fatigability, neck stiffness, backache, and low back pain and headache. Particularly, neck stiffness, headache, and low back pain are the main menopausal symptoms in Japanese women [1]. Hormone replacement therapy (HRT) has been widely accepted to relieve menopausal symptoms $[2,3]$, while it is associated with an increased risk of breast cancer [3,4]. Therefore, an effective and safe alternative health product for women is needed to improve menopausal symptoms. Various safe alternative health products such as isoflavones, St John's wort, and Royal Jelly (RJ) can provide relief of menopausal symptoms [5-7].

Among them, RJ has been long used as a nutritional supplement and its safety has been demonstrated by several clinical studies [8-10], so RJ supplementation could be a good option for those having concerns about HRT. Traditionally, RJ has been used to improve menopausal symptoms [11], and case reports have revealed that the menopausal symptoms such as hot flashes, anxiety, irritation, fatigability, neck stiffness, low back pain, and headache were improved with $\mathrm{RJ}$ supplementation in menopausal women [7]. However, the placebo-controlled studies of RJ on menopausal symptoms have not been reported. RJ contains a considerable amount of proteins, free amino acids, lipids, vitamins, minerals, and unique fatty acids such as (E)-10-hydroxy-2-decenoic acid (10HDA) and 10-hydroxydecanoic acid (10HDAA) [12]. It is reported that RJ and 10HDA have estrogenic effect and 
agonist activity for estrogen receptor (ER) $\beta[13,14]$; hence one of the mechanisms for improvement of physical and psychiatric symptoms in menopause is considered to be the estrogenic effect.

Here, a randomized double-blind placebo-controlled study was conducted in order to determine the effect of RJ on menopausal symptoms, specifically in postmenopausal women.

\section{Material and Methods}

2.1. Participants. The study was carried out in accordance with the principles outlined in the Declaration of Helsinki. Written informed consent was obtained from all the participants before enrollment. The study protocol was approved by Shiba Palace Clinic Ethics Committee (Tokyo, Japan). This study has been conducted between July 2015 and December 2015 (UMIN000018842). Study volunteers have been recruited from volunteer bank of Research Center for Immunological Analysis, Inc. (Okayama, Japan) and CROèe Inc. (Tokyo, Japan). All participants were healthy Japanese postmenopausal women (at least 12 month have passed since their last menstrual period) with estrogen level more stable than premenopausal women. Major eligibility criteria were having undergone natural menopause within 5 years, having self-rating depression scale score $<49$, having hot flash score $>0$, and being diagnosed as having menopausal symptoms which require no treatment by obstetrician. Major exclusion criteria were having undergone treatment with sexual hormones, nonhormonal climacteric drugs, or any treatment to alleviate menopausal symptoms, having undergone treatment with chemical or plant-derived medicines, having severe diseases (e.g., of heart, liver, kidneys, digestive system, or metabolic diseases), or having undergone intake of drugs and supplements which could influence the outcome of this study.

2.2. Study Design. This study has been conducted as a double-blind randomized controlled trial. Forty-two women were randomized into the placebo group and enzymetreated RJ (YRP-M-141122) group by randomly distributing numerical codes. After randomization, the codes were kept in the possession of one employee of Yamada Bee Company, Inc., who was not involved in the present study until completion. It can be noted that sample size calculation was not estimated because the preliminary study was not conducted. The enzyme-treated RJ powder was obtained from Yamada Bee Company, Inc. (Okayama, Japan). It was standardized to include minimum 3.5\% 10HDA and minimum 0.6\% 10HDAA and provided as tablets. Each tablet contained $200 \mathrm{mg}$ of enzyme-treated RJ. The enzyme-treated RJ group received four tablets once a day $(800 \mathrm{mg} /$ day $)$ for 12 weeks. For placebo preparations, dextrin was used instead of enzyme-treated RJ. The placebo tablets were also administered once a day for 12 weeks. Additionally, post intervention follow-up was conducted for 4 weeks. During this follow-up, all study participants had not ingested enzyme-treated RJ or placebo.

2.3. HPLC Analysis. 10HDA and 10HDAA in the RJ powder were analyzed as follows. RJ tablets were crushed in a

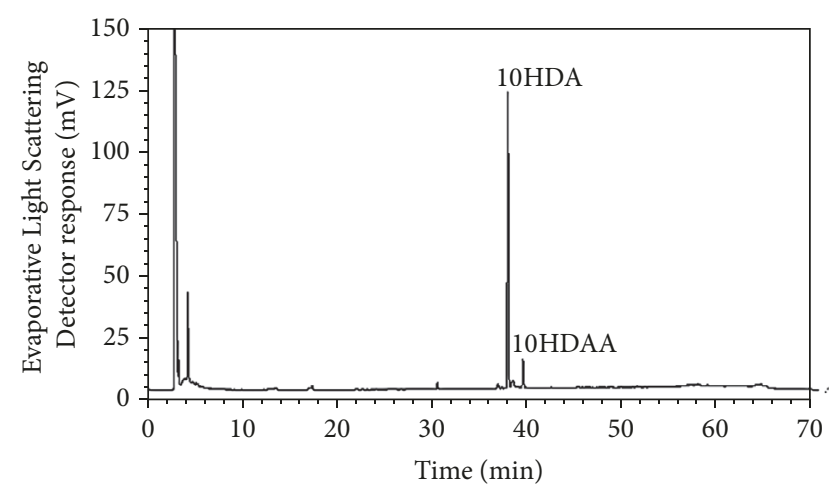

FIGURE 1: The HPLC chemical fingerprint for the extract of enzymetreated RJ powder.

mortar and extracted with methanol under agitation at room temperature. The concentration of 10HDA and 10HDAA in the extract was measured using an HPLC system (Shimadzu, Kyoto, Japan) equipped with a Cosmosil 5C18-AR-II column $4.6 \mathrm{~mm}$ ID $\times 250 \mathrm{~mm}$ (Nacalai Tesque, Kyoto, Japan) at $40^{\circ} \mathrm{C}$ under a constant flow rate $(1.0 \mathrm{~mL} / \mathrm{min})$ of $25 \%$ acetonitrile in $0.1 \%$ TFA (mobile phase). Detection was performed with PDA detector at $215 \mathrm{~nm}$ for 10HDA and evaporative light scattering detector (ELSD, $30^{\circ} \mathrm{C}$ ) for 10HDAA. The HPLC chemical fingerprint for the extract can be seen in Figure 1, which was recorded by $\operatorname{ELSD}\left(50^{\circ} \mathrm{C}\right)$, with the gradient solvent system of methanol \{5\% (5 min hold), 5-90\% (45 min linear gradient), $100 \%$ (10 min hold), and 5\% (10 min hold)\} in $0.1 \%$ TFA at a flow rate of $1.0 \mathrm{~mL} / \mathrm{min}$.

2.4. Evaluation of Menopausal Symptoms. Menopausal symptoms questionnaire of Japanese women [15] (Figure 2) was used to assess menopausal symptoms. This assessment tool of menopausal symptoms is based on common complaints in Japanese women which include facial skin blushing and upper body (hot flashes), easy to sweat (sweating), difficulty getting to sleep (insomnia), difficulty staying asleep (light sleep), irritability, anxiety, often irritated by trifles (anxious trifles), feeling unhappy or depressed (depressive mood), fatigue, eye strain, memory problems (forgetfulness), dizziness, palpitations, chest tightness, headache, neck stiffness, backache and low back pain, joint pain, cold hands and feet, numbness in the legs or arms, and sensitive to sounds. Symptoms like irritation, dizziness, backache and low back pain, and joint pain had high priority for investigation based on the result of our previous studies which have shown an improvement with RJ treatment [16]. Other menopausal symptoms were the secondary outcome. The Visual Analog Scale (VAS) was used to assess each abovedescribed menopausal symptom. The participants answered menopausal symptoms questionnaire of Japanese women during the week before randomization and after 4, 8, and 12 weeks of daily intake and 4 weeks after intervention.

2.5. Statistical Analysis. Statistical analysis was performed with JMP software (version 5.1, SAS Institute). The independent $t$-test was used to compare the changes from baseline to 
For each symptom listed below, please mark the degree of severity during the past week.

Facial skin blushing and upper body (hot flashes)

(Not at all)

(Severe)

Easy to sweat (sweating)

Difficulty getting to sleep (insomnia)

Difficulty staying asleep (light sleep)

Irritability

Anxiety

Often irritated by trifles (anxious trifles)

Feeling unhappy or depressed (depressive mood)

Fatigue

Eye strain

Memory problems (forgetfulness)

Dizziness

Palpitation

Chest tightness

Headache

Neck stiffness

Backache and low back pain

Joint pain

Cold hands and feet

Numbness in the legs or arms

Sensitive to sounds

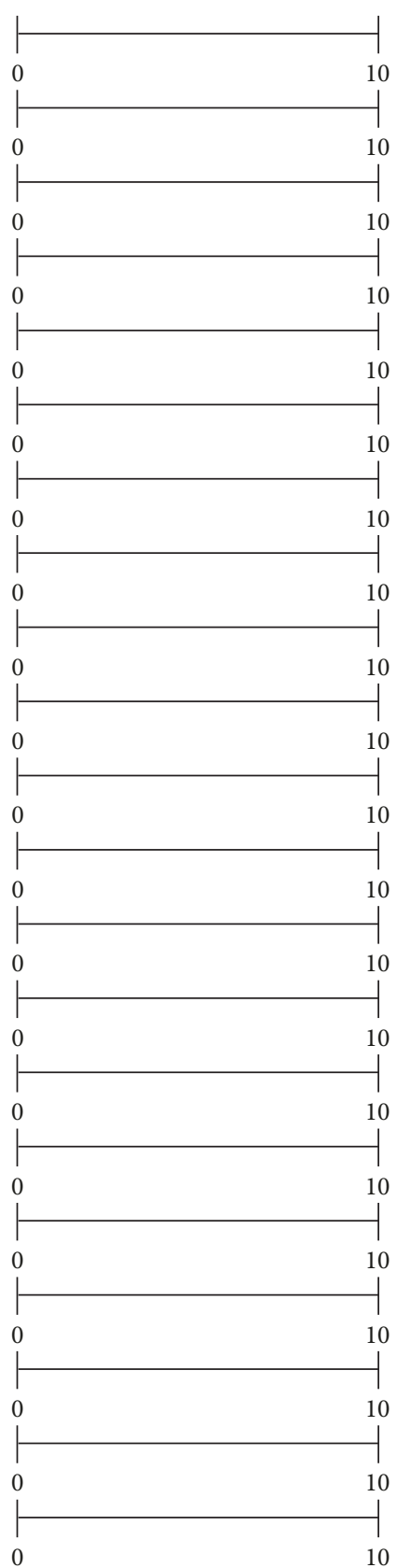

FIGURE 2: Menopausal symptoms questionnaire of Japanese women.

those after intervention between the two groups. $P<0.05$ was considered significant for all data analyses.

\section{Results}

3.1. Participants. All of the 42 women ( 21 randomized into placebo-treated group and 21 randomized into the enzymetreated RJ group) completed the trial (Figure 3). The baseline characteristics like age, body mass index (BMI), postmenopausal periods, and each menopausal symptom score were not significantly different between the two groups (Table 1). During the study, no side effects associated with enzyme-treated RJ intake were observed.

3.2. Effects of Enzyme-Treated RJ Treatment on Menopausal Symptoms. There were significant differences in the anxiety score $(P=0.046)$ and backache and low back pain score $(P=0.040)$ between $800 \mathrm{mg} /$ day enzyme-treated $\mathrm{RJ}$ and placebo-treated groups after 12 weeks of administration, and no significant differences were found between the two 


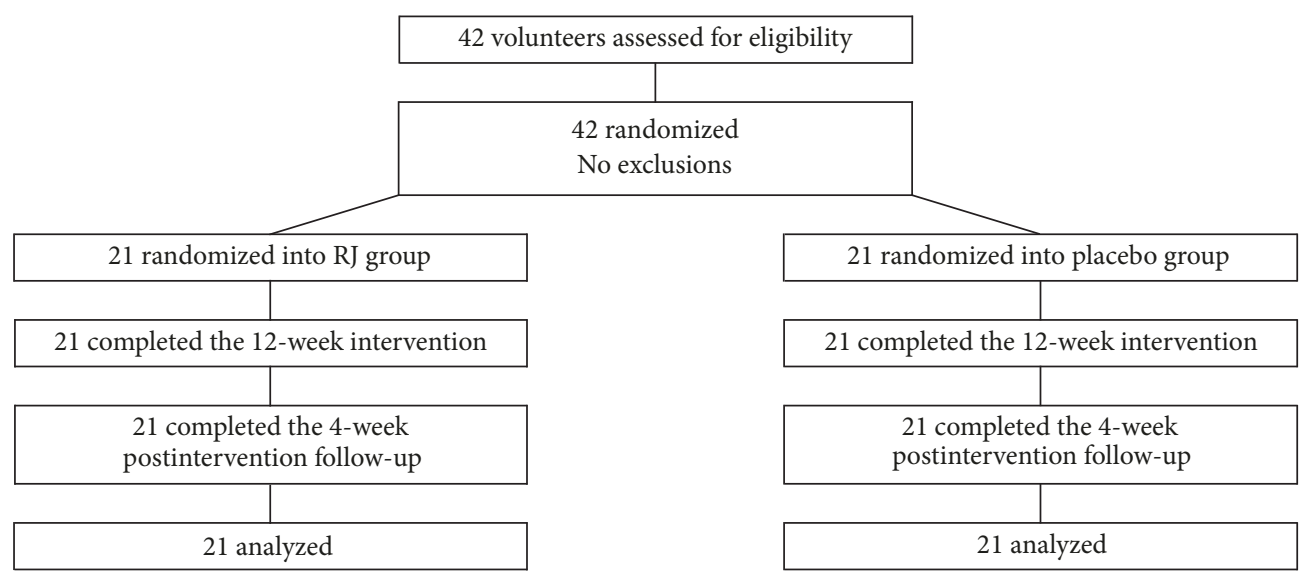

Figure 3: Trial flow diagram.

TABLE 1: Baseline characteristics of the study population.

\begin{tabular}{|c|c|c|c|}
\hline & Placebo & RJ & $P$ \\
\hline Subject number & 21 & 21 & \multirow{4}{*}{ N. D } \\
\hline \multicolumn{3}{|l|}{ Postmenopausal period } & \\
\hline $1-3$ years & 16 & 15 & \\
\hline $3-5$ years & 5 & 6 & \\
\hline Age (years) & $54.4 \pm 3.0$ & $54.4 \pm 2.6$ & 1.000 \\
\hline BMI $\left(\mathrm{kg} / \mathrm{m}^{2}\right)$ & $21.2 \pm 2.6$ & $21.0 \pm 3.0$ & 0.790 \\
\hline \multicolumn{4}{|l|}{ Each menopausal VAS score } \\
\hline Hot flashes & $41.5 \pm 35.0$ & $44.2 \pm 32.9$ & 0.797 \\
\hline Sweating & $44.6 \pm 30.2$ & $52.0 \pm 30.1$ & 0.436 \\
\hline Insomnia & $27.3 \pm 27.4$ & $30.7 \pm 26.1$ & 0.684 \\
\hline Light sleep & $42.0 \pm 28.5$ & $43.2 \pm 23.0$ & 0.873 \\
\hline Irritability & $32.5 \pm 33.0$ & $34.0 \pm 25.0$ & 0.871 \\
\hline Anxiety & $28.7 \pm 26.6$ & $30.5 \pm 22.5$ & 0.818 \\
\hline Anxious trifles & $35.1 \pm 31.1$ & $35.5 \pm 25.8$ & 0.970 \\
\hline Depressive mood & $30.2 \pm 24.3$ & $33.4 \pm 26.3$ & 0.685 \\
\hline Fatigue & $39.0 \pm 23.7$ & $42.5 \pm 22.0$ & 0.620 \\
\hline Eye strain & $60.7 \pm 31.7$ & $58.6 \pm 27.8$ & 0.821 \\
\hline Forgetfulness & $58.3 \pm 28.2$ & $57.7 \pm 26.4$ & 0.942 \\
\hline Dizziness & $27.1 \pm 29.0$ & $27.4 \pm 28.7$ & 0.970 \\
\hline Palpitation & $25.9 \pm 27.9$ & $18.4 \pm 22.2$ & 0.342 \\
\hline Chest tightness & $17.2 \pm 20.7$ & $7.1 \pm 10.1$ & 0.051 \\
\hline Headache & $46.9 \pm 33.8$ & $34.9 \pm 29.4$ & 0.229 \\
\hline Neck stiffness & $65.4 \pm 31.7$ & $63.6 \pm 31.6$ & 0.854 \\
\hline Backache and low back pain & $47.0 \pm 34.7$ & $47.2 \pm 30.9$ & 0.989 \\
\hline Joint pain & $39.0 \pm 33.3$ & $37.5 \pm 26.6$ & 0.875 \\
\hline Cold hands and feet & $38.4 \pm 28.0$ & $41.7 \pm 30.4$ & 0.717 \\
\hline Numbness in the legs or arms & $25.1 \pm 28.9$ & $21.8 \pm 26.5$ & 0.703 \\
\hline Sensitive to sounds & $31.5 \pm 32.2$ & $18.9 \pm 20.5$ & 0.137 \\
\hline
\end{tabular}

RJ, enzyme-treated Royal Jelly. The values are means \pm SD. 


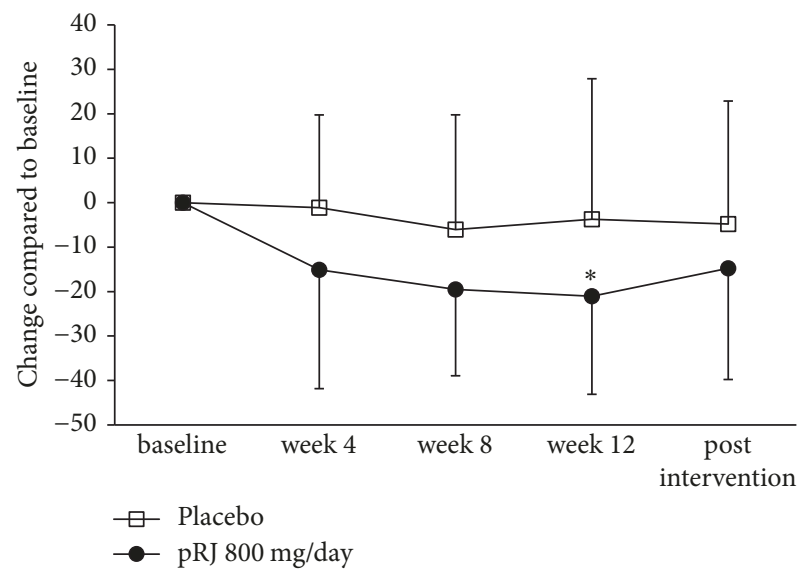

(a) Anxiety

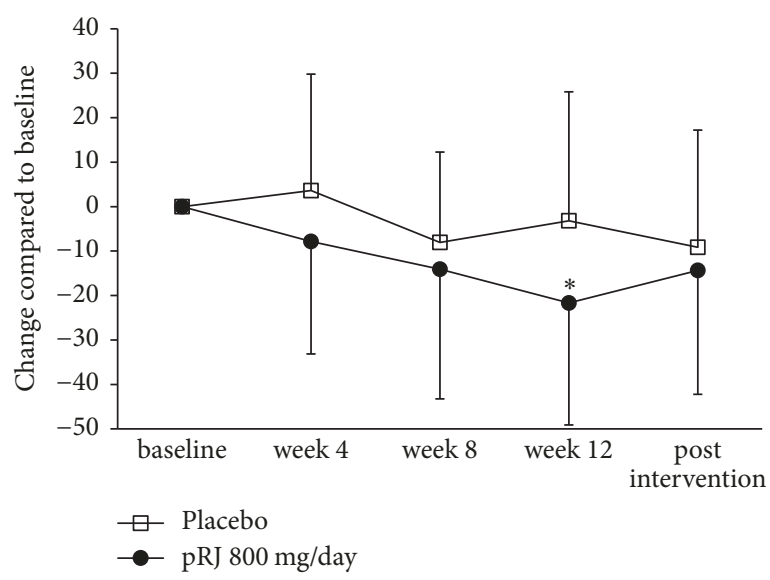

(b) Backache and low back pain

FiguRE 4: Enzyme-treated RJ treatment improves the score of menopausal symptoms such as backache and low back pain and anxiety. A $P$ value of $<0.05$ was considered statistically significant compared to placebo and is indicated by the asterisk. All values are mean \pm SD.

groups after intervention (Figure 4 and Table 2). Regarding hot flashes, there were significant differences between the two groups after 8 weeks of administration and no significant differences after 12 weeks of administration (Table 2). No significant change was observed in any other menopausal symptom score between the two groups (Table 2).

\section{Discussion}

The present study showed that enzyme-treated RJ supplementation with doses of $800 \mathrm{mg} /$ day has improved the anxiety score and backache and low back pain score in healthy Japanese postmenopausal women. Hot flashes are the most common symptom of menopause in Western countries [17]. However, Melby et al. showed that the main menopausal symptoms in Japanese women are not hot flashes but neck stiffness, headache, and low back pain [1], so the relief of backache and low back pain confirmed in the present study is considered to be meaningful in Japanese women.

The beneficial effects of RJ on menopausal symptoms were reported only in controlled before-after studies [7], so the present study is the first double-blind randomized placebo-controlled trial to investigate the effect of enzymetreated RJ on menopausal symptoms. The case report of Kushima et al. showed that RJ intake for 10-14 days of 500 or $1,000 \mathrm{mg} /$ day dose improved anxiety and backache and low back pain [7], and our previous study suggested that enzyme-treated RJ intake for 8 weeks of $800 \mathrm{mg}$ /day dose improved psychological symptoms and backache and low back pain compared with those before intake [16]. These findings support the result of the present study.

Although it is not clear exactly how enzyme-treated RJ improves menopausal symptoms, we presume that its estrogenic activity could play an important role for selective ER modulators $[13,14]$. Krezel et al. described that an anxiety behavior increased in ER $\beta$-deficient female mice [18], and Imwalle et al. showed that $\operatorname{ER} \beta$-deficient female mice had significantly lower serotonin content in several brain regions (the bed nucleus of the stria terminalis, preoptic area, and hippocampus) [19]. The 10HDA and 10HDAA content of RJ showed ER $\beta$-selective agonist activity [13], and Ito et al. suggested that the intraperitoneal injection of 10HDA has been effective in protecting against anxiety in stressinducible depression-like mouse model [20]. In light of these reports, ER $\beta$ agonist activity of $10 \mathrm{HDA}$ and 10HDAA could be one contributor in reducing anxiety through an increase in serotonin. The serotonin has long been considered to have an important role in the control of pain [21], so the one mechanism for amelioration of low back pain may be the increase in serotonin. Additionally hypoperfusion is also believed to be other cause of low back pain [22, 23]. Our unpublished data had shown that 10HDAA treatment increased blood flow in rats; thus the improvement of blood flow due to 10HDAA may contribute to improving low back pain.

10HDA and 10HDAA have effect on $\mathrm{ER} \beta$ as described above [13] but have little effect on $\operatorname{ER} \alpha$ [13] which is a risk factor for cancer $[24,25]$, so RJ is considered to be a safer alternative health product.

This study has some limitations which have to be pointed out: (1) there was a reduced number of participants (21 postmenopausal women per group), (2) lower effective dose and dose dependency were unclear, (3) the subjects were only postmenopausal women, and (4) the detailed mechanism and component for improvement of menopausal symptoms were not characterized. Further studies are needed to investigate the above issues.

\section{Conclusion}

This study demonstrates that enzyme-treated RJ supplementation with doses of $800 \mathrm{mg} /$ day has beneficial effects on menopausal symptoms such as anxiety, backache, and low back pain in Japanese postmenopausal women.

\section{Conflicts of Interest}

Takashi Asama, Hidenori Matsuzaki, Shinobu Fukushima, Tomoki Tatefuji, and Ken Hashimoto are employees of 
TABLE 2: Effect of enzyme-treated RJ treatment on menopausal symptoms.

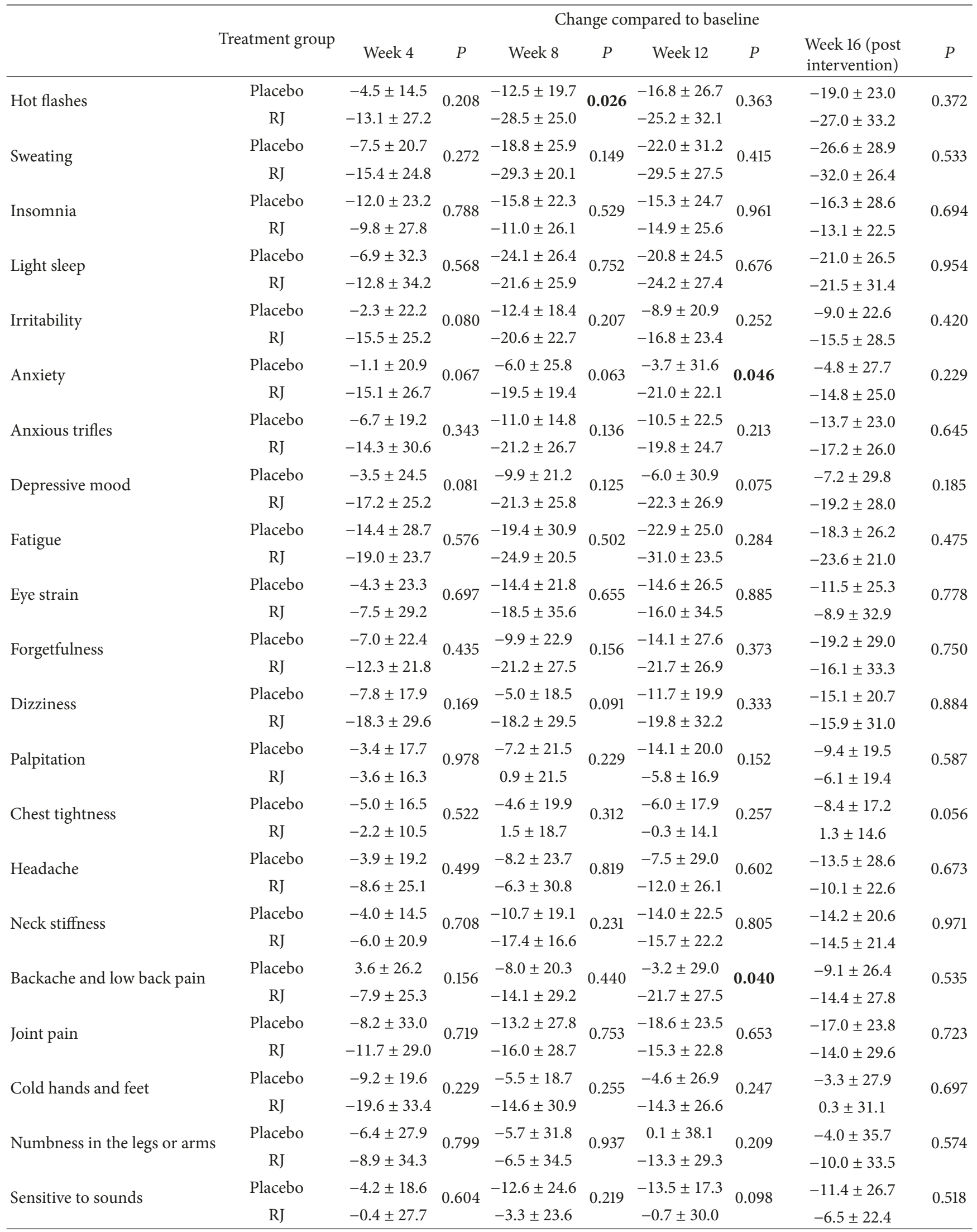

Menopausal symptoms scores were assessed monthly with menopausal symptoms questionnaire of Japanese women (Visual Analog Scale); RJ, enzyme-treated Royal Jelly. All values are mean \pm SD. 
Yamada Bee Company, Inc. Takashi Takeda received a medical advisory fee from Yamada Bee Company, Inc.

\section{Acknowledgments}

The authors are grateful to Dr. Ana-Maria Oprea and Tasuku Ito for carefully proofreading the manuscript and for providing the fingerprint of RJ, respectively. They would like to thank Drs. Hiroshi Inooka, Tomoki Ikuta, Hiroko Tani, and Yuka Kimura for useful discussions.

\section{References}

[1] M. K. Melby, M. Lock, and P. Kaufert, "Culture and symptom reporting at menopause," Human Reproduction Update, vol. 11, no. 5, pp. 495-512, 2005.

[2] D. W. Sturdee and A. Pines, "Updated IMS recommendations on postmenopausal hormone therapy and preventive strategies for midlife health," Climacteric, vol. 14, no. 3, pp. 302-320, 2011.

[3] North American Menopause Society, "The 2012 hormone therapy position statement of the North American Menopause Society," Menopause, vol. 19, no. 3, pp. 257-271, 2012.

[4] R. T. Chlebowski, G. L. Anderson, M. Gass et al., "Estrogen plus progestin and breast cancer incidence and mortality in postmenopausal women," Journal of the American Medical Association, vol. 304, no. 15, pp. 1684-1692, 2010.

[5] Y.-B. Ye, Z.-L. Wang, S.-Y. Zhuo et al., "Soy germ isoflavones improve menopausal symptoms but have no effect on blood lipids in early postmenopausal Chinese women: A randomized placebo-controlled trial," Menopause, vol. 19, no. 7, pp. 791-798, 2012.

[6] K. Abdali, M. Khajehei, and H. R. Tabatabaee, "Effect of St John's wort on severity, frequency, and duration of hot flashes in premenopausal, perimenopausal and postmenopausal women: A randomized, double-blind, placebo-controlled study," Menopause, vol. 17, no. 2, pp. 326-331, 2010.

[7] K. Kushima, N. Hasegawa, and E. Ogawa, "Effects of Royal Jelly on autonomic imbalance in menopausal women," The World of Obstetrics and Gynecology, vol. 25, pp. 439-443, 1973.

[8] S. Taavoni, F. Barkhordari, A. Goushegir, and H. Haghani, "Effect of Royal Jelly on premenstrual syndrome among Iranian medical sciences students: A randomized, triple-blind, placebocontrolled study," Complementary Therapies in Medicine, vol. 22, no. 4, pp. 601-606, 2014.

[9] S. Pourmoradian, R. Mahdavi, M. Mobasseri, and E. Faramarzi, "Effects of royal jelly supplementation on glycemic control and oxidative stress factors in type 2 diabetic female: a randomized clinical trial," Chinese Journal of Integrative Medicine, vol. 20, no. 5, pp. 347-352, 2014.

[10] H. Morita, T. Ikeda, K. Kajita et al., "Effect of royal jelly ingestion for six months on healthy volunteers," Nutrition Journal, vol. 11, no. 1, article 77, 2012.

[11] E. P. Cherniack, "Bugs as drugs, part 1: insects. The "new" alternative medicine for the 21st century?" Alternative Medicine Review, vol. 15, no. 2, pp. 124-135, 2010.

[12] C. Mateescu and D. Barbulescu, "Enhanced nutritive, functional and therapeutic action of combined bee products in complex food supplements," Romanian Biotechnological Letters, vol. 4, pp. 163-172, 1999.

[13] K.-M. Suzuki, Y. Isohama, H. Maruyama et al., "Estrogenic activities of fatty acids and a sterol isolated from royal jelly,"
Evidence-Based Complementary and Alternative Medicine, vol. 5, no. 3, pp. 295-302, 2008.

[14] S. Mishima, K.-M. Suzuki, Y. Isohama et al., "Royal jelly has estrogenic effects in vitro and in vivo," Journal of Ethnopharmacology, vol. 101, no. 1-3, pp. 215-220, 2005.

[15] Japan society of obstetrics and gynecology, "Menopausal symptoms questionnaire of Japanese women," Acta Obstetrica et Gynaecologica Japonica, vol. 53, pp. 13-14, 2001.

[16] T. Asama, M. Yamaga, and S. Saito, "Validation of questionnarires as food supplements efficacy evaluation method by Royal Jelly and Bee energy ${ }^{\circledR}$ intake," Jpn Pharmacol Ther, vol. 44, pp. 93-99, 2016.

[17] M. Lock, "Ambiquities of aging: Japanese experience and perceptions of menopause," Culture, Medicine and Psychiatry, vol. 10, no. 1, pp. 23-46, 1986.

[18] W. Krezel, S. Dupont, A. Krust, P. Chambon, and P. F. Chapman, "Increased anxiety and synaptic plasticity in estrogen receptor $\beta$-deficient mice," Proceedings of the National Acadamy of Sciences of the United States of America, vol. 98, no. 21, pp. 1227812282, 2001.

[19] D. B. Imwalle, J.-Å. Gustafsson, and E. F. Rissman, "Lack of functional estrogen receptor $\beta$ influences anxiety behavior and serotonin content in female mice," Physiology \& Behavior, vol. 84, no. 1, pp. 157-163, 2005.

[20] S. Ito, Y. Nitta, H. Fukumitsu et al., "Antidepressant-like activity of 10-hydroxy-trans-2-decenoic acid, a unique unsaturated fatty acid of royal jelly, in stress-inducible depression-like mouse model," Evidence-Based Complementary and Alternative Medicine, vol. 2012, Article ID 139140, 6 pages, 2012.

[21] L. Bardin, "The complex role of serotonin and 5-HT receptors in chronic pain," Behavioural Pharmacology, vol. 22, no. 5-6, pp. 390-404, 2011.

[22] S. Kanai, R. Susuki, H. Abe, and H. Okano, "Static magnetic fields used to treat low back pain, monitored by thermography," Orthopedics \& Traumatology, vol. 46, no. 3, pp. 764-766, 1997.

[23] S. Kanai, H. Okano, and R. Susuki, “Therapeutic effectiveness of static magnetic fields for low back pain monitored with thermography and deep body thermometry," Journal of the Japan Society of Pain Clinicians, vol. 5, pp. 5-10, 1998.

[24] K. S. Korach, "Estrogen receptor knock-out mice: molecular and endocrine phenotypes," Journal of the Society for Gynecologic Investigation, vol. 7, pp. S16-S17, 2017.

[25] N. Andruska, X. Zheng, X. Yang, W. G. Helferich, and D. J. Shapiro, "Anticipatory estrogen activation of the unfolded protein response is linked to cell proliferation and poor survival in estrogen receptor $\alpha$-positive breast cancer," Oncogene, vol. 34, no. 29 , pp. $3760-3769,2015$. 


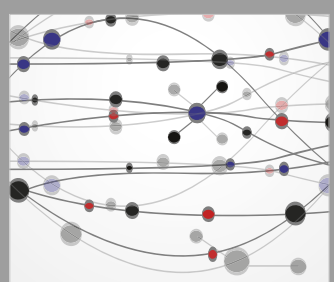

The Scientific World Journal
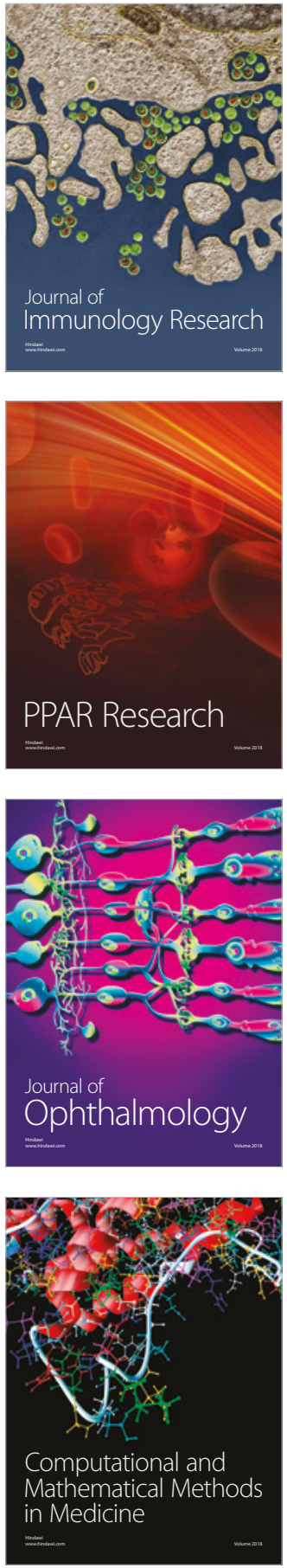

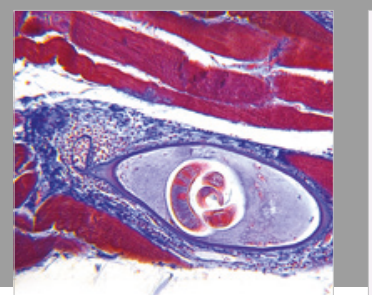

Gastroenterology Research and Practice

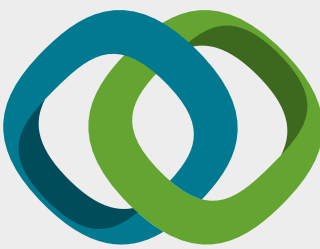

\section{Hindawi}

Submit your manuscripts at

www.hindawi.com
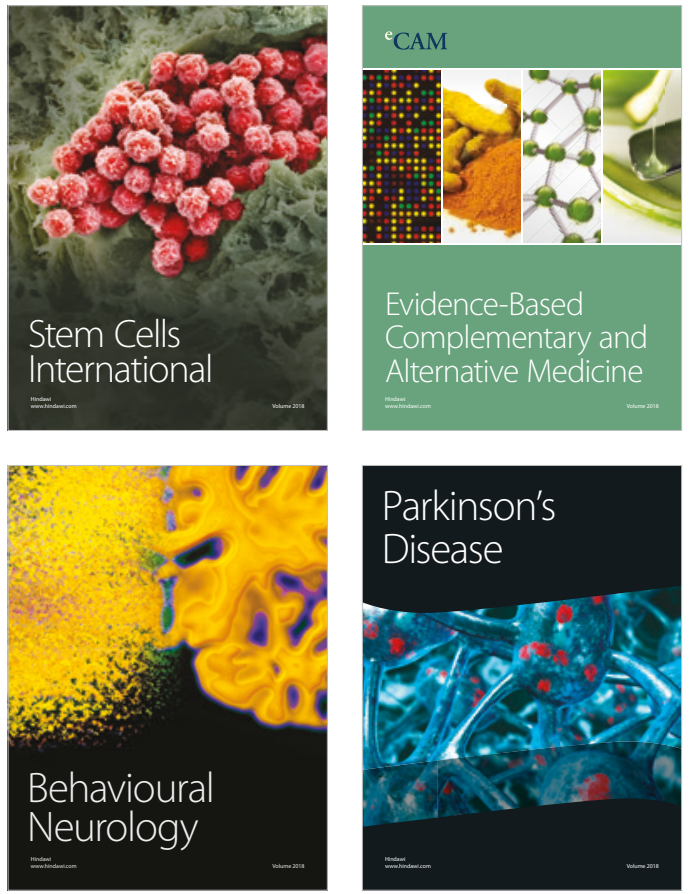

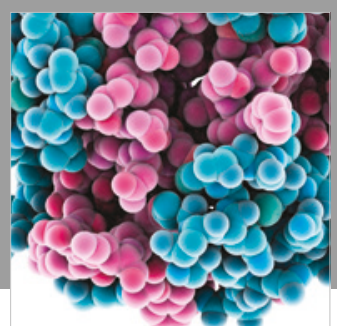

ournal of

Diabetes Research

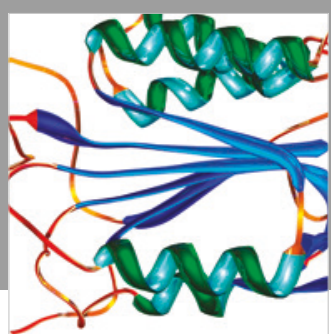

Disease Markers
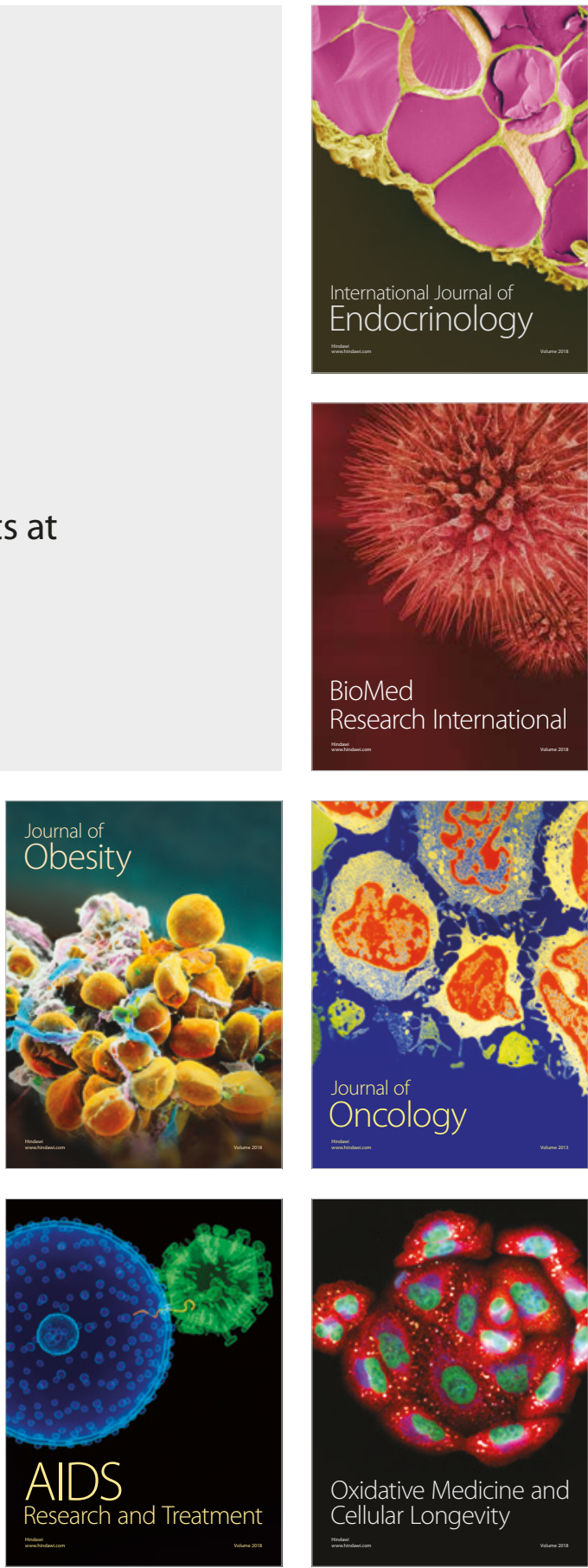